Estudios Constitucionales, Año 12, No 1, 2014, pp. 567-585.

ISSN 07180195

Centro de Estudios Constitucionales de Chile Universidad de Talca

"Análisis de la sentencia Artavia Murillo y otros ('Fecundación in vitro') vs. Costa Rica de la Corte Interamericana de Derechos Humanos"

Eduardo A. Chía y Pablo Contreras

\title{
ANÁLISIS DE LA SENTENCIA ARTAVIA MURILLO Y OTROS ("FECUNDACIÓN IN VITRO") VS. COSTA RICA DE LA CORTE INTERAMERICANA DE DERECHOS HUMANOS*
}

\author{
Analysis of the Case ARTaVia Murillo and others \\ (“IN Vitro FERTILIZATION”) v. COSTA RicA. \\ InTER-AMERICAN COURT OF Human RightS
}

\author{
Eduardo A. Chía** \\ Universidad Nacional Andrés Bello - Chile \\ eduardo.chia@gmail.com \\ Pablo Contreras $s^{* *}$ \\ Universidad Alberto Hurtado - Chile \\ pcontreras@nlaw.northwestern.edu
}

\section{INTRODUCCIÓN}

El siguiente comentario analiza la sentencia Artavia Murillo y otro ("Fecundación in vitro") vs. Costa Rical (en adelante "Artavia"), de la Corte Interamericana de Derechos Humanos (en adelante "Corte IDH”). Se divide en dos secciones. La primera examina el problema de la (no) aplicación de la doctrina del margen de apreciación en la decisión del caso concreto. Tal postura adoptada por la Corte IDH repercute en el grado de discreción que tienen (o no) las autoridades nacionales de los Estados Parte para definir el contenido concreto de los derechos fundamentales bajo la Convención Americana de Derechos Humanos (en adelante

\footnotetext{
* Trabajo recibido el 31 de octubre de 2013 y aprobado el 4 de diciembre de 2013.

** Abogado. Licenciado en Ciencias Jurídicas, Universidad Nacional Andrés Bello; candidato a Magíster en Filosofía Universidad de Chile; Profesor de Introducción al Derecho, Universidad Nacional Andrés Bello.

*** Abogado. Licenciado en Ciencias Jurídicas y Magíster en Gobierno y Sociedad, Universidad Alberto Hurtado; Máster en Derecho (LL.M.) y candidato a Doctor en Derecho (S.J.D.), Northwestern University; Profesor de Derecho, Universidad Alberto Hurtado. Sitio web: <http://www.pcontreras.net>

1 Artavia Murillo y otros ("Fecundación in vitro") vs. Costa Rica, Sentencia de excepciones preliminares, fondo, reparaciones y costas, Ser. C No 257, Nov. 28, 2012 (en adelante "Artavia").
} 
"Convención"). La segunda sección, por otra parte, analiza la interpretación que hace la Corte IDH del artículo 4 de la Convención, en lo que se refiere al derecho a la vida y el rechazo a considerar al feto como titular del mismo.

El comentario concluye que el caso Artavia tiene dos grandes implicancias para el sistema interamericano de derechos humanos. En primer lugar, que la Corte IDH evita emplear una doctrina de deferencia a los Estados Parte de la Convención, como la doctrina del margen de apreciación. En segundo lugar, que el nasciturus no es titular del derecho a la vida del artículo 4 de la Convención y que tal ratio decidendi puede afectar las obligaciones de los Estados en lo que dice relación con la mantención de las reglas punitivas que criminalizan sin posibilidad de excepción la interrupción del embarazo de la mujer.

\section{Margen de apreciación y derecho a la Vida ANTE La Corte InTERAMERICANa De Derechos Humanos \\ 1. Sobre el margen de apreciación}

En materia interpretativa, una doctrina significativa a la hora de indagar el grado de discreción nacional de que pueden gozar los Estados Parte, en materia de derechos humanos, es la denominada tesis del "margen de apreciación". Se trata de un desarrollo jurisprudencial del Tribunal Europeo de Derechos Humanos (en adelante "TEDH”) en virtud del cual los Estados Parte de la Convención Europea de Derechos Humanos (en adelante "CEDH") pueden definir, en principio, los límites y restricciones de los derechos contenidos en el tratado, siempre sujeto a la revisión internacional. Se trata de una doctrina que articula la deferencia internacional del TEDH respecto de las decisiones internas de los Estados. El margen comprende "la noción de que cada sociedad tiene derecho a cierta latitud en la resolución de los conflictos inherentes entre derechos individuales e intereses nacionales o entre distintas convicciones morales" 2 .

El margen de apreciación nacional ha sido especialmente utilizado en temáticas donde existe un profundo disenso al interior de una sociedad ${ }^{3}$. Ciertas materias que en Chile se suelen denominar "valorativas" caen especialmente dentro de esta categoría, entre ellas, la decisión respecto al momento en que comienza la protección jurídica de la vida humana. Sin embargo, al menos en la experiencia comparada, el margen de apreciación también es empleado en otros casos, como aquellos que

\footnotetext{
2 Benvenisti (1999), pp. 843-844.

3 LegG (2012), pp. 85 y ss.
} 
dicen relación con restricciones a la libertad de expresión ${ }^{4}$, casos de blasfemia ${ }^{5}$, derechos de la comunidad LGBTI 6 , o controversias respecto de vestimentas o símbolos religiosos en la esfera pública ${ }^{7}$. Con distintos grados e intensidades, el margen opera como una doctrina de deferencia o condescendencia en la que la decisión regulatoria recae en las autoridades nacionales. Esto se explica por razones de subsidiariedad de la protección de los sistemas regionales de derechos humanos ${ }^{8}$.

El margen de apreciación es una doctrina propiamente europea, pese a que existe cierta escasa aplicación en el ámbito interamericano9 . El TEDH ha recurrido al margen de apreciación nacional en materia de la protección de la vida del que está por nacer, como se revisa más adelante. La Corte IDH, al contrario, desechó tal argumento y procedió a resolver directamente el caso Artavia en base a consideraciones de proporcionalidad. Esto se explicará a continuación.

\section{La negación del margen de apreciación en la decisión de la Corte}

En el reciente caso Artavia Murillo y otros vs. Costa Rica ${ }^{10}$, la Corte IDH debió decidir si la decisión nacional de prohibir, sin posibilidades de excepción, las técnicas de fertilización in vitro (en adelante, "FIV") era compatible con la Convención. A este respecto, la Comisión Interamericana de Derechos Humanos argumentó, principalmente, que tal medida violaba los artículos 11.2 y 17.2 de la Convención ${ }^{11}$, al constituir una injerencia arbitraria a los derechos a la vida

\footnotetext{
4 Sentencia del TEDH, Handyside v. United Kingdom, App. No 5493/72, Dic. 7, 1976.

5 Sentencia del TEDH, Otto-Preminger-Institut v. Austria, App. No 13470/87, Sept. 20, 1994.

6 Sentencia del TEDH, Dudgeon v. Reino Unido, App. No 7525/76, Feb. 24, 1983; sentencia del TEDH, Christine Goodwin v. Reino Unido, App. No 28957/95, Jul. 11, 2002, 974 y sentencia del TEDH, I v. Reino Unido, App. No 25680/94, Jul. 11, 2002. (La sigla hace mención a la comunidad compuesta por lesbianas, gays, bisexuales, transgéneros e intersexuales).

7 Sentencia del TEDH, Sahin v. Turquía, App. No 44774/98, Nov. 10, 2005 (en relación a prohibiciones de uso velo islámico en una universidad pública) y sentencia del TEDH, Lautsi v. Italia, App. o 30814/06, Mar. 18, 2011 (en relación a los crucifijos instalados en escuelas públicas).

8 Carozza (2003), pp. 39 y ss.

9 Sobre la teoría del margen de apreciación, véase LEGG (2012). En el ámbito interamericano, véase AcosTA, Paola Andrea \& Núnez Poblete (2012). Para una comparación entre Europa y América sobre el margen de apreciación, véase Contreras (2012).

10 Artavia Murillo y otros ("Fecundación in vitro") vs. Costa Rica, cit.

11 Id., 93. "Artículo 11. Protección de la Honra y de la Dignidad. [...] 2. Nadie puede ser objeto de injerencias arbitrarias o abusivas en su vida privada, en la de su familia, en su domicilio o en su correspondencia, ni de ataques ilegales a su honra o reputación".
} 
privada y familiar, por un lado, y el derecho a formar una familia, por el otro, en relación con el principio de igualdad (artículo 24) ${ }^{12}$. Por su parte, el Estado costarricense argumentó que la decisión buscaba proteger el derecho a la vida tal como se consagra en el artículo 4.1 de la Convención ${ }^{13}$, el cual, de acuerdo con sus argumentaciones, se le reconocería al embrión preimplantacional. Para sostener aquella pretensión, el Estado demandado se fundó en un enunciado normativo de la Convención atingente a la controversia sobre la FIV, a saber, que el derecho a la vida "estará protegido por la ley y, en general, a partir del momento de la concepción”.

A este respecto, la tesis del margen de apreciación fue explícitamente invocada en el caso "Artavia" por el Estado de Costa Rica. Como se lee en la sentencia, el Estado argumentó que "i) no 'existe consenso en relación con el estatuto jurídico del embrión'; ii) 'no existe consenso sobre el inicio de la vida humana, [por tanto] debe también otorgarse margen de apreciación sobre la regulación de la técnica' de la FIV, y iii) no es válido el argumento de que 'como existen otros Estados que, por omisión legislativa, permiten la práctica de la [FIV], Costa Rica ha perdido su margen de apreciación"14.

El argumento era plausible respecto de la decisión estatal sobre cómo proteger el derecho a la vida en Costa Rica pero contrastaba con la utilización de la misma doctrina en los casos europeos, donde el margen de apreciación era invocado para autorizar - no prohibir- las prácticas de FIV. Sin embargo, tanto el voto de mayoría como el de minoría se demarcaron de un análisis de margen de apreciación. Para la mayoría, tras determinar el alcance del artículo 4 de la Convención ${ }^{15}$, se debió examinar la proporcionalidad de la prohibición total para utilizar técnicas de FIV16. En su razonamiento, el juicio de proporcionalidad se encuentra completamente desvinculado de consideraciones del margen de apreciación. En efecto, sólo lue-

\footnotetext{
"Artículo 17. Protección a la Familia [... 2. Se reconoce el derecho del hombre y la mujer a contraer matrimonio y a fundar una familia si tienen la edad y las condiciones requeridas para ello por las leyes internas, en la medida en que éstas no afecten al principio de no discriminación establecido en esta Convención”.

12 "Artículo 24. Igualdad ante la Ley. Todas las personas son iguales ante la ley. En consecuencia, tienen derecho, sin discriminación, a igual protección de la ley”.

13 "Artículo 4. Derecho a la Vida. 1. Toda persona tiene derecho a que se respete su vida. Este derecho estará protegido por la ley y, en general, a partir del momento de la concepción. Nadie puede ser privado de la vida arbitrariamente".

14 Artavia Murillo y otros vs. Costa Rica, cit., 9170.

15 Id., 99171 y ss.

16 Artavia Murillo y otros vs. Costa Rica, cit., 99272 y ss.
} 
go de concluir que los derechos a la libertad personal, vida privada y autonomía reproductiva habían sido afectados en forma severa ${ }^{17}$-cuestión que constituye una violación a la Convención-, la mayoría de la Corte estimó que no es "[...] pertinente pronunciarse sobre los alegatos del Estado respecto a que contaría con un margen de apreciación para establecer prohibiciones como la efectuada (por los tribunales de Costa Rica) [...]"18.

El voto de minoría del juez Eduardo Vio Grossi también omite la aplicación de la doctrina del margen de apreciación. El razonamiento de este juez discurre, por una parte, sobre una interpretación alternativa del alcance normativo del artículo 4 de la Convención y, por la otra, en una crítica a la tesis de la mayoría y la metodología que emplearon. Para Vio Grossi, "[...] la vida de una persona existe desde el momento en que ella es concebida o, lo que es lo mismo, que se es 'persona' o 'ser humano' desde el 'momento de la concepción', lo que ocurre con la fecundación del óvulo por el espermatozoide. A partir de esto último se tiene, entonces, según aquélla, el 'derecho... a que se respete (la) vida' de 'toda persona' y, consecuentemente, existe la obligación de que se proteja ese derecho [...]"19. Pese a señalar que la Corte IDH tiene limitaciones jurisdiccionales en materias donde no hay consensos médicos y morales ${ }^{20}$-cuestión que parece conectarse con la idea de la autorrestricción judicial-, su razonamiento no incluye ninguna consideración sobre el margen de apreciación respecto a la controversia planteada.

A pesar de lo anterior, debe reconocerse que existen algunos elementos que son parte de los criterios del margen de apreciación -aun cuando la Corte no los relacione con tal doctrina. Por ejemplo, el voto de mayoría utilizó como estrategia argumentativa referirse a la práctica de la generalidad de los Estados Parte de la Convención, con el objeto de ilustrar la interpretación del artículo 4, negando que la protección del embrión constituya una barrera a las técnicas de FIV ${ }^{21}$. Con ello se buscó configurar un consenso regional a favor de estas prácticas. Aquello no es fútil, puesto que el elemento del consenso de los Estados Parte es uno de los componentes básicos del margen de apreciación. Dicho en términos muy sencillos: mientras mayor consenso regional en contra de una medida estatal restrictiva de

17 Id., 99274, pp. 314-5.

18 Artavia Murillo y otros vs. Costa Rica, cit., 9316 (énfasis nuestro).

19 Artavia Murillo y otros vs. Costa Rica, cit., p. 12 del voto disidente del juez Eduardo Vio Grossi, cursivas en el original.

20 Id., p. 28.

21 Artavia Murillo y otros vs. Costa Rica, cit., 9256. 
derechos exista, mayor es la intensidad del escrutinio judicial que le corresponde a las Cortes regionales ${ }^{22}$. El voto de minoría critica la real configuración de dicho consenso y afirma que no sería la mayoría de los Estados Parte de la Convención los que autorizan las técnicas de FIV.

\section{Margen de apreciación europeo: resumen del estado de la cuestión}

En el sistema europeo de protección internacional de los derechos humanos, el TEDH ha fallado distintas causas en que ha debido definir el grado de discreción que poseen las autoridades nacionales para la protección de la vida del no-nacido y los problemas de titularidad que se asocian a ello. No es el propósito de este comentario analizar la totalidad de la jurisprudencia en esta materia ${ }^{23}$. En este apartado sólo se ilustrará, mediante una breve reseña, la manera en que el TEDH ha lidiado con estos asuntos y qué estándares ha fijado para definir el margen de apreciación de los Estados Parte en tales asuntos.

Uno de los casos más relevantes al respecto es Vo vs. Francia ${ }^{24}$, donde el TEDH reconoció el derecho a la vida de la madre y, a partir de ello, mediante la ligazón íntima de ésta con el producto de la concepción, se reconoció cierta protección al no-nacido; antes bien, siempre a partir del derecho de la madre y no porque el feto sea persona o haya sido beneficiario de la protección que otorga el artículo 2 del $\mathrm{CEDH}^{25}$. En relación con el margen de apreciación de los Estados, sostuvo el TEDH que la determinación del comienzo de la vida humana -y su protección por el ordenamiento jurídico- cae bajo la discreción de los Estados Parte del $\mathrm{CEDH}^{26}$. Posteriormente, en Evans vs. Reino Unido ${ }^{27}$, el TEDH tuvo que resolver un caso referido a la oposición de una mujer a que una clínica de fertilización

\footnotetext{
22 LeGG (2012), pp. 120 y ss.

23 Sobre los estándares europeos en materia de aborto e información de salud reproductiva, véase WATSON (2013), pp. 173-176.
}

24 Sentencia del TEDH, Vo vs. Francia, App. No 53924/00, julio 8, 2004.

25 Id., 985. "[...] Having regard to the foregoing, the Court is convinced that it is neither desirable, nor even possible as matters stand, to answer in the abstract the question whether the unborn child is a person for the purposes of Article 2 of the Convention ('personne' in the French text). As to the instant case, it considers it unnecessary to examine whether the abrupt end to the applicant's pregnancy falls within the scope of Article 2, seeing that, even assuming that that provision was applicable, there was no failure on the part of the respondent State to comply with the requirements relating to the preservation of life in the public-health sphere $[\ldots]$.

26 Id., 982.

27 Sentencia del TEDH, Evans vs. Reino Unido, App. No 6339/05, abril 10, 2007. 
asistida destruyera -amparada en una legislación inglesa que regulaba la FIV-seis embriones congelados como consecuencia de un tratamiento fallido. En relación con la doctrina en comento, el TEDH decidió que constituye parte del margen de apreciación de los Estados Parte la decisión de establecer o no legislaciones sobre las técnicas de FIV y de fijar las reglas que articulan los intereses en colisión ${ }^{28}$. De otra parte, en el caso $A, B$ y $C$ vs. Irlanda ${ }^{29}$, tres mujeres demandaron a Irlanda ante el TEDH porque este país prohíbe a través de la vía punitiva interrumpir un embarazo por razones sanitarias. Ante esta situación, las mujeres debieron viajar hasta el Reino Unido para realizarse un procedimiento de emergencia. En tales circunstancias, el TEDH declaró que no existe un derecho a interrumpir un embarazo bajo el artículo 8 del CEDH, que establece el derecho al respeto a la vida privada y familiar. Esto es relevante puesto que, así como en Vo. vs. Francia el TEDH no reconoció de modo manifiesto la titularidad del no-nacido para ejercer el derecho a la vida, en $A, B, C$ vs. Irlanda, el TEDH rechazó la afirmación explícita respecto a que las mujeres tendrían un derecho a interrumpir su embarazo a partir de una interpretación del derecho al respeto a la vida privada y familiar previsto en el artículo 8 del CEDH. Asimismo, el TEDH reafirmó que la tesis respecto a que la determinación del momento en que la vida debe ser protegida por el derecho es una cuestión que cae bajo el margen de apreciación de los Estados Parte del tratado en comento ${ }^{30}$.

En dicho contexto, dos casos recientes son relevantes en relación al análisis de Artavia. En S.H. y otros vs. Austria ${ }^{31}$, el TEDH declaró como compatible con el CEDH la prohibición de FIV con espermios y óvulos de terceros. De manera patente, señaló que existe un margen de apreciación estatal en materias donde existe una importante controversia sobre asuntos morales y éticos, tal como el que es posible hallar en el debate sobre las técnicas de reproducción asistida ${ }^{32}$. Finalmente, en Costa y Pavan vs. Italia ${ }^{33}$, el TEDH declaró incompatible la prohibición de diagnóstico preimplantacional por ser inconsistente con la autorización de interrupción del embarazo por enfermedad del feto. En este caso, a su vez,

28 Id., $9981-2$.

29 Sentencia del TEDH, $A, B$ y $C$ vs. Irlanda, App. № 25579/05, diciembre 16, 2010. Sobre este caso, véase el análisis de UndurRaga (2011), pp. 377-407.

30 Id., 9237.

31 Sentencia del TEDH, S.H. y otros vs. Austria, App. No 57813/00, noviembre 3, 2011.

32 Id., $9996-7$.

33 Sentencia del TEDH, Costa y Pavan vs. Italia, App. No 54270/10, agosto 28, 2012. 
reafirmó el mismo margen de apreciación que había reconocido previamente en S.H. y otros vs. Austria, cual es, que la definición de asuntos morales controvertidos puede quedar a discreción de los Estados Parte del CEDH ${ }^{34}$.

Esta breve reseña de la jurisprudencia europea permite mostrar cómo el TEDH -fallando casos relacionados a Artavia, en cuanto al objeto de la controversia- busca articular estándares de deferencia internacional bajo la doctrina del margen de apreciación.

\section{La conclusión de la Corte IDH y las diferencias con el caso europeo}

Volviendo al caso Artavia, pese a que existió un análisis de la práctica estatal en la ejecución de la Convención, parece no controvertido que la doctrina del margen de apreciación no cumple rol alguno en la decisión. El voto mayoritario estimó que la protección sin excepciones del embrión es desproporcionada y no se dispuso a analizar el grado de discreción que los Estados podrían tener al momento de fijar tal medida ${ }^{35}$. Los casos que se han seguido ante el TEDH y que hemos reseñado aquí, utilizan el margen de apreciación para validar decisiones estatales que autorizan estas prácticas. La principal diferencia radica en el grado de protección de los derechos involucrados. Para el TEDH, el silencio del tratado respecto de la protección de la vida del embrión -junto a otras consideraciones en torno al consenso- permiten dar deferencia a los Estados Parte sobre materias como la interrupción del embarazo, las técnicas de FIV o el diagnóstico preimplantacional. La Corte IDH, por otra parte, autoriza los procedimientos de FIV sin recurrir al margen de apreciación. Para arribar a ello, estimó que la prohibición categórica y sin excepciones de la vida del embrión constituye una medida que interfiere desproporcionadamente con otros derechos consagrados en la Convención.

Una conclusión provisional respecto al empleo del estándar de discreción nacional sería la siguiente: la doctrina del margen de apreciación, tras Artavia, no parece tener buen futuro -al menos dentro del sistema interamericano.

\section{II.I LA INTERPRETACIÓN DEL ARTÍCULO 4 DE LA CONVENCIÓN}

El comentario ahora se abocará a un elemento que incidió de manera determinante en las consideraciones previamente expuestas, esto es, la interpretación que la Corte IDH efectuó del artículo 4 de la Convención. Dicha interpretación, en

34 Id., $9967-8$.

35 En tal sentido, se ha sostenido que la Corte IDH resolvería de forma "maximalista”. Véase PAúl (2013). 
el contexto del sistema interamericano protección a los derechos humanos, no es una cuestión baladí. Al respecto, cabe recordar que en Latinoamérica y el Caribe se encuentran las legislaciones punitivas más restrictivas del planeta en torno la interrupción de un embarazo. Salvo el caso de Uruguay y algunas entidades federativas de México ${ }^{36}$, todos los países del sistema poseen modelos de indicaciones con alcances bastante restringidos para interrumpir un embarazo. El caso paradigmático de esta situación lo tenemos en Chile, Estado que a nivel global, junto a Nicaragua, República Dominicana, El Salvador, Malta y El Vaticano, no autoriza bajo ninguna circunstancia que una mujer interrumpa un embarazo.

En general, los Estados para justificar la intensidad de las prohibiciones punitivas han hecho una interpretación extensiva del derecho a la vida a partir de las lecturas de sus constituciones nacionales. A partir de ello, han determinado que las reglas sobre derecho a la vida alcanzan a proteger jurídicamente a los embriones y a los fetos. Por ende, si los fetos o embriones son titulares del derecho a la vida, no se justifica bajo ningún respecto el establecimiento de reglas que permitan interrumpir un embarazo, ya que, de lo contrario, se conculcaría injustificadamente el derecho a la vida de los embriones y los fetos.

aquel es el estado de la cuestión, hoy por hoy, en la mayor parte de los Estados que pertenecen al Sistema Interamericano de Derechos Humanos respecto a los alcances del derecho a la vida y su relación con los embriones y los fetos. Es por ello que la sentencia acá analizada es de particular interés para una revisión de aquellos aspectos del fallo que inciden de manera directa en la discusión constitucional, a nivel nacional, sobre el estatuto jurídico del embrión y su relación con la prohibición punitiva de la interrupción voluntaria del embarazo.

En ese sentido, como ya se venía fallando de modo sistemático y desde hace bastante tiempo por parte de la jurisprudencia constitucional comparada ${ }^{37}$, la

36 Cabe precisar que EE.UU. y Canadá son los países que tienen las regulaciones más amplias para interrumpir un embarazo en América, siendo un derecho constitucional de las mujeres. No obstante, estos países no pertenecen al Sistema Interamericano de Derechos Humanos pues no han ratificado la Convención; Canadá ni siquiera forma parte de la Organización de Estados Americanos.

37 En especial véanse las siguientes sentencias de las Cortes Constitucionales comparadas: Roe v. Wade 410 U.S. 113 [1973] (EE.UU.); sentencia No 53/1985 (España); sentencias BverfGE 39,1 [1975] у 88 BVerfGE 203 [1993] (Alemania); sentencia No 146/2007 y su acumulada No 147/2007 (México); Sentencia C-355/2006 (Colombia).

En relación con los fallos del BVerfG, cabe prevenir que éstos no reconocen explícitamente en sus pronunciamientos que el nonato sea titular de derechos. Pese a lo anterior, en la sentencia de 1993, el BVerfG, aun considerando que la interrupción del embarazo es un injusto penal (por ende antijurídico), estableció un permiso para su realización. Éste se fundó en que no es exigible [Unzumurbarkei] a la mujer 
Corte IDH confirmó que el feto no es un sujeto de derecho. ${ }^{38}$ Para llegar a tal conclusión, subyace en los razonamientos de la Corte IDH una tesis controvertida, referida a que los derechos sólo pueden ser ejercidos por personas, ya que únicamente éstas pueden ser las beneficiarias de la normatividad que otorgan los principios constitucionales que adscriben derechos. Siendo ello así, el nonato no está legitimado para el ejercicio de derechos en forma autónoma, como sí lo están las personas nacidas y completas. En tal sentido, la decisión de la Corte IDH, en términos filosóficos, asimiló lo que ya había indicado Kant ${ }^{39}$, cuando se preguntó el cómo conocemos. Ante ello, el autor explicó que sólo un sujeto (agente) posee la autoconsciencia que determina y condiciona la actividad cognoscitiva, porque es él quien construye los objetos del conocimiento. De esto se sigue que, en principio, es necesaria una consciencia para saber que se goza del beneficio normativo que entregan los principios de Derecho constitucional.

Aunque lo decidido por la Corte IDH es una cuestión altamente polémi$\mathrm{ca}$, donde no existe un consenso moral ni político, el Derecho constitucional comparado había ido construyendo de forma progresiva un marco normativo jurídicamente justificatorio respecto a la no-titularidad del feto para ejercer derechos básicos. Antes bien, este marco nunca se había establecido de manera tan categórica, como esta vez lo hizo la Corte IDH. Así, por vía ejemplar, podemos observar lo fallado por la Corte Constitucional de Colombia, que efectuó una distinción entre la vida como un bien (moral), entendido como la valiosidad del proceso de fenómenos en que se despliega la existencia biológica y en el que se ejecutan las actividades de las personas en el mundo. Y, por otra, la vida como bien jurídico, expresada en la forma del derecho constitucional a la vida, el cual opera (en lenguaje de derechos subjetivos) como la exigencia (a particulares y al Estado) de no privar arbitraria o injustificadamente a un sujeto del disfrute de los

que en ciertas circunstancias sobrelleve un embarazo, pues de lo contrario se dotaría de prevalencia categórica al derecho del nasciturus por sobre los derechos de la mujer, violándose de esa forma la prohibición de infradimensionamiento [untermassverbot]. De igual modo, dijo que el Derecho penal no es el mecanismo idóneo para tutelar y proteger la vida humana intrauterina. Es decir, es compatible con la Constitución [Alemana] que el legislador tutele y proteja jurídicamente la vida humana intrauterina, no sólo a través de disposiciones penales de carácter represivas y violentas, sino que es constitucionalmente aceptable que la tutela se efectúe mediante medidas preventivas de conserjería [Berutung] que tiendan a animar a la grávida a llevar a término el embarazo. Luego, mediante ese mecanismo, se protegería la vida del que está por nacer.

38 Artavia Murillo y otros vs. Costa Rica, cit., 9264. "[...] La Corte ha utilizado diversos métodos de interpretación, los cuales han llevado a resultados coincidentes en el sentido de que el embrión no puede ser entendido como una persona para efectos del artículo 4.1 de la Convención Americana [...]”.

39 Kant (2003), pp. 330 y ss. 
fenómenos de la existencia humana ${ }^{40}$ : "[...] la vida tiene diferentes tratamientos normativos, pudiendo distinguirse el derecho a la vida consagrado en el articulo 11 constitucional ${ }^{41}$, de la vida como bien jurídico protegido por la Constitución. El derecho a la vida supone la titularidad para su ejercicio y dicha titularidad, como la de todos los derechos está restringida a la persona humana, mientras que la protección de la vida se predica incluso respecto de quienes no han alcanzado esta condición [...]"42. En términos muy similares, también efectuando una negación de la calidad de sujeto de derecho al feto, el Tribunal Constitucional español sostuvo. "[...] los argumentos aducidos por los recurrentes no pueden estimarse para fundamentar la tesis de que al nasciturus le corresponda también la titularidad del derecho a la vida [...]"43.

De otra suerte, situación especial es la de EE.UU., toda vez que en Roe vs. Wade la Corte Suprema estadounidense no se pronunció expresamente sobre la titularidad del nasciturus, desde el momento que la Corte determinó que el nonato no es una "persona constitucional", siendo solamente protegible por el derecho a partir del estado gestacional de la "viabilidad" 44 .

Distinto es el caso de la sentencia de la Corte Suprema mexicana, la cual no emitió juicios concretos sobre la titularidad para ejercer derechos por parte del nonato, puesto que la Carta Fundamental de México no regula en forma expresa el derecho a la vida. Pese a ello, el magistrado Sergio Valls, en voto concurrente, además de distinguir entre vida como bien (moral) y el derecho a la vida, se refirió de forma explícita a la titularidad del no nacido aduciendo que: "[...] el derecho a la vida, como derecho subjetivo, supone la titularidad para su ejercicio, la cual está restringida necesariamente a la persona humana, en contraposición a la protección de la vida en general, que si comprende a quienes no han alcanzado esa calidad, esto es, a los no-nacidos, pues se trata de vida potencial [...]"45.

Por consiguiente, al menos en el plano del Derecho constitucional comparado, el asunto de que embrión/feto no equivale a sujeto, ya había sido resuelto. De ahí

40 Sobre esta interpretación, en especial vid. FiguerOA (2008), pp. 261-300.

41 Art. 11. Constitución Colombia: El derecho a la vida es inviolable. No habrá pena de muerte.

42 C-355/2006 de la Corte Constitucional de Colombia.

43 Sentencia No 53/1985 Tribunal Constitucional de España.

44 Esta decisión fue re-afirmada en los siguientes casos (entre varios otros): City of Akron v. Akron Center for Reproductive Health, Inc., 462 U.S. 416 (1983), Thornburgh v. American College of Obstetricians and Gynecologists, 106 S. Ct. 2169 (1986).

45 Voto concurrente que formula el Ministro Sergio Valls Hernández, en la acción de inconstitucionalidad $146 / 2007$ y su acumulada $147 / 2007$, p. 2. 
que el nonato esté imposibilitado de ser un titular de derechos. Ello, básicamente porque no posee el mismo status moral que una persona nacida, racional, autosuficiente y completa, por tanto, merece una tutela jurídica diferenciada sobre la base de la "potencia" de vida que contingentemente representa. En la práctica, esto se ha traducido en la asunción de deberes estatales activos que dan protección a la vida humana, como un objeto de protección.

Ahora bien, la cuestión conceptual de la persona tampoco es algo baladí. A este respecto, Rolando Tamayo y Salmorán ${ }^{46}$ ha subrayado que en el plano jurídico el concepto persona conlleva, esencialmente, una significación técnicojurídica que denota aquella entidad que puede actuar en la vida jurídica, o sea, que puede desempeñar un rol en la vida que envuelve el derecho. Esto, por su parte, tiene una explicación etimológica, ya que el significado original etrusco de persona fue "máscara" (phersu), con lo cual se designaba la cara del actor que representaba una escena ${ }^{47}$. De ahí que la significación técnica de persona apele a una categoría dramática.

Independiente de esta nota histórica, hoy en día, lo importante es tener en cuenta que persona es, para el derecho, lo que la comunidad jurídica determinó debe ser una persona, en correlación necesaria con aquellos estándares desarrollados en el devenir del tiempo y en armonía con los principios constitucionales sobre los que se organiza la comunidad -tales como los estándares establecidos por la propia Corte IDH. De acuerdo a estas consideraciones, los fetos y embriones, dados sus caracteres constitutivos asignados por la comunidad jurídica: i) están imposibilitados de desempeñar un papel significativo en la vida jurídica; ii) no son personas por decisión de la comunidad política, cuestión que con posterioridad ha sido especificada a través de una resolución jurídica. Por eso, cuando la Corte IDH dice en sus párrafos 222 y 223 -luego de analizar diversas disposiciones de Derecho internacional aplicando variados criterios de interpretación constitucional- que "[...] no es factible sostener que un embrión sea titular y ejerza los derechos consagrados en dichos artículos (de la Convención) [...]", siendo "[...] improcedente otorgar el estatus de persona al embrión [...]"48, simplemente reafirma las ideas que se acaban de exponer.

Esta conclusión de la Corte IDH no sólo es correcta jurídicamente, sino que también encuentra apoyo en ciertos sectores de la filosofía moral. En efecto, existe

46 Tamayo y Salmorán (1996), pp. 293-311.

47 Duff (1938).

48 Artavia Murillo y otros vs. Costa Rica, cit., 99222 y 223 (énfasis nuestro). 
una corriente de autores que ha sostenido que el concepto persona está circunscrito a la agencia, idea que implica asignar a una entidad -previa determinación deliberada de la comunidad política- ciertas propiedades moralmente relevantes determinantes de la sustantividad de la condición humana. Estas últimas dicen relación con experiencias que hacen posible el disfrute de los fenómenos de la existencia biológica en el mundo. Tal como se ha presentado, la cuestión de la agencia como presupuesto de la personalidad moral no es un asunto del todo-onada. De hecho, ésta presupone una gradualidad en el desarrollo moral, cuestión que se cristaliza mediante diversos grados de intensidad a partir del evento de la viabilidad fetal, considerado este último como hito relevante, pues implica que el feto puede sobrevivir fuera del vientre materno con o sin soporte de la tecnología médica ${ }^{49}$ y desde el cual comienza a gestarse de modo progresivo el desarrollo de lo que en filosofía de la mente se conoce como consciousness $^{50}$.

De esa manera, para estos autores, la adquisición escalonada de propiedades morales prima facie relevantes tales como la capacidad cognoscitiva, la reciprocidad social, la posibilidad de representación de lo futuro con el propósito de para materializar planes e ideales morales de vida, el hecho de recordar eventos retrospectivamente -en tanto posesión de continuidad psíquica- y, por sobre todo, la capacidad de autodeterminación como agente moral, dan cuenta de la existencia de ciertos rasgos vitales y procesos mentales que los fetos y los seres vivos en gestación no poseen, sino que puramente en forma de potencia contingente.

Dichas caracterizaciones de la persona moral no son arbitrarias, pues se fundan en la idea de estatus moral como elemento ontológico y normativo constitutivo de ésta, cuyas principales significaciones han sido construidas y propuestas por filósofos morales contemporáneos tales como Singer ${ }^{51}$, Warren ${ }^{52}$, Feinberg ${ }^{53}$, y Tooley ${ }^{54}$. Estos autores postulan que aquellas condiciones morales básicas, prima facie relevantes, permiten adscribir derechos básicos a una entidad.

Siendo ello así, si observamos con atención las argumentaciones vertidas en el voto de mayoría de la sentencia de la Corte IDH, podemos afirmar con seguridad

\footnotetext{
49 Warren (2000), p. 353.

50 Sobre consciousness, fundamental resulta consultar la obra de Velmans \& SCHNEIDER (2007). En particular, véase el artículo de TREVARTHEN \& REDDY (2007), pp. 41 ss.

51 Singer (1993).

52 WARREN (1996), pp. 434-440.

53 Feinberg (1986), pp. 256-293.

54 Tooley (2009).
} 
que las reflexiones antes expuestas fueron implícitamente incorporadas en el razonamiento al momento de determinar que el goce de tutela jurídica por parte del feto: "[...] no es algo absoluto (del todo-o-nada) sino gradual e incremental según el desarrollo de éste [...]"55. A partir de ello, los magistrados concluyeron que la interpretación más pertinente del artículo 4.1 de la Convención, que reglamenta el derecho a la vida, admite exclusiones en su aplicación, siendo posible su concreción en intensidad normativa atendiendo el gradual desarrollo del embrión a partir de la implantación de éste en el útero de la mujer; adquiriendo el beneficio total de las reglas de derecho sólo una vez que se nace, ya que sólo a partir de ese entonces se es persona en el sentido jurídicamente relevante.

Dicho eso, ¿por qué estas consideración podrían ser relevantes para la discusión sobre la despenalización de la interrupción del embarazo en nuestro país?

Pues bien, aun cuando la decisión de la Corte IDH versa sobre un tema ajeno al aborto, varios aspectos resolutivos del fallo son de suma relevancia para la argumentación jurídica en torno a la permisibilidad legal de la interrupción de un embarazo. Aquello es así pues las razones justificatorias esbozadas por Corte IDH echaron abajo dos de las principales estrategias argumentativas del pensamiento conservador para oponerse a la licitud del aborto consentido, a saber: i) que el feto es titular del derecho a la vida, de lo cual derivaban la inconstitucionalidad de toda regla que autorizara interrumpir un embarazo en algunos supuestos y concurriendo ciertas exigencias; ii) que el derecho constitucional a la vida del feto es absoluto, debiendo prevalecer siempre por sobre los derechos constitucionales de la mujer.

Con respecto al primer argumento conservador $i$ ): cabe decir que el fallo de la Corte IDH fue categórica al momento de zanjar la discusión en torno a la no titularidad del feto para ser beneficiario de las reglas de Derecho. Asimismo, como antes lo explicamos, la Corte IDH explicitó algo que ya estaba presente en el ideario ético e histórico-político, a saber, que el embrión no es sujeto de Derecho y, por ende, tampoco persona. No obstante, no por ello debe quedar excluido de la protección jurídica como un objeto del Derecho. A este respecto, los magistrados de la Corte IDH, al igual como antes lo habían hecho los jueces de las Cortes Constitucionales comparadas, han entendido que corresponde al Estado un deber activo tutelar de la vida humana intrauterina. Por consiguiente, en la medida que el desarrollo gestacional del producto de la concepción alcanza un mayor grado de proximidad a la condición psicobiológica y moral de las personas nacidas, ese interés estatal en proteger la vida en gestación se incrementa y se vuelve legítimo.

55 Artavia Murillo y otros vs. Costa Rica, cit., 99264 (énfasis nuestro). 
A este respecto, no debemos dejar mencionar que, con la conclusión antes mencionada, la Corte IDH evitó incurrir en la común falacia non sequitur ${ }^{56}$, traducida en lo siguiente: del hecho que los nonatos merezcan algún tipo de tutela jurídica por parte del Estado en razón de la potencia de vida que contingentemente representan, no por ello es posible concluir que necesariamente tengan condición de titulares de derechos y, menos aún, que sean personas.

En relación al segundo argumento del pensamiento conservador ii): su refutación se deriva del razonamiento expuesto en el punto previo. En efecto, la Corte IDH volvió a subrayar algo que ya estaba presente en el ideario ético e histórico-político, incluso presente en nuestras intuiciones básicas, esto es, “[...] que entender el derecho a la vida como absoluto no tiene sustento en la Convención [...]"57. Pensar lo contrario, conlleva la negación de otros derechos que protege la Convención ${ }^{58}$. Asimismo, la Corte IDH insistió en hacer presente que la defensa de la protección sin excepción del derecho a la vida es contraria al objeto y fin de la Convención, cual es, la tutela de los derechos humanos ${ }^{59}$.

Estas aseveraciones de la Corte IDH, negadas históricamente por nuestro Congreso Nacional, por nuestro Tribunal Constitucional y por nuestra Corte Suprema, son relevantes para el robustecimiento de los derechos de las mujeres, pues reconocen que éstas son portadoras de derechos en igualdad de condiciones. Esto es significativo no sólo desde un punto de vista jurídico, sino que también político y ético, ya que implica reconocimiento para las mujeres, tanto de ciudadanía, como de personalidad moral.

En definitiva, es de esperar que los aspectos resolutivos del fallo de la Corte IDH, en torno al estatuto jurídico del embrión, junto a sus prevenciones sobre los derechos sexuales y reproductivos en particular y los derechos humanos de las mujeres, en general, sean considerados y aprehendidos por nuestra institucionalidad política. Esto es, además, parte del parámetro que la misma Corte IDH ha

\footnotetext{
56 No debemos olvidar que esta falacia sí fue cometida por el voto de mayoría del Tribunal Constitucional chileno cuando conoció del Requerimiento de inconstitucionalidad deducido en contra de algunas disposiciones de las "Normas Nacionales sobre Regulación de la Fertilidad", aprobadas por el Decreto Supremo No 48, de 2007, del Ministerio de Salud (conocido como caso "Píldora del Día Después"). Sentencia Tribunal Constitucional, Rol No 740-2007.

57 Artavia Murillo y otros vs. Costa Rica, cit., 99273 (énfasis nuestro).

58 Artavia Murillo y otros vs. Costa Rica, cit., 99258. “[...] El objeto y fin del artículo 4.1. de la Convención es que no se entienda el derecho a la vida como un derecho absoluto, cuya alegada protección pueda justificar la negación total de otros derechos [...]”.

59 Artavia Murillo y otros vs. Costa Rica, cit., 99259 (énfasis nuestro).
} 
fijado a través de la doctrina del control de convencionalidad: tanto los órganos judiciales - establecido en el caso Almonacid vs. Chile ${ }^{60}$ - como los colegisladores -determinado en el caso Gelman vs. Uruguay ${ }^{61}$ - se encuentran obligados a incorporar este estándar de derechos humanos en las decisiones internas. Contando con la interpretación autoritativa del artículo 4.1 de la Convención, debiésemos ser próximamente testigos de una amplia deliberación democrática con el objeto y fin de establecer una legislación acabada sobre la interrupción legal del embarazo, pues tal como se trata de mostrar, dos de los principales argumentos utilizados por el pensamiento conservador para oponerse a una reforma legal que autorice el aborto consentido fueron desechados por la institucionalidad jurisdiccional máxima sobre derechos humanos en el continente.

\section{ConClusiones}

La Corte IDH ha dictado una importante sentencia que precisa las obligaciones internacionales de los Estados Parte de la Convención en materia del derecho a la vida establecido en el artículo 4 de dicho instrumento. Este comentario trató de precisar los alcances de la sentencia en dos ámbitos: el margen de apreciación de los Estados y el estatus del nasciturus ante la Convención Americana.

En relación con el primer asunto, lo que se observa es que la Corte ha evitado emplear la doctrina del margen de apreciación como estándar de revisión de una materia de alta controversia moral. En claro contraste con su par europeo, la Corte prefiere emplear el principio de proporcionalidad como test de escrutinio internacional en el (in)cumplimiento de las obligaciones de la Convención. De esta forma, rechazó las reclamaciones de Costa Rica para que actuara deferentemente en la regulación de las técnicas de reproducción asistida y supervisó intensamente la restricción de derechos a través de la proporcionalidad.

En relación con el segundo asunto, la Corte IDH precisó el contenido protegido por el artículo 4.1 de la Convención. En primer término, sostuvo que el nasciturus no es titular del derecho a la vida. Para efectos de la Convención Americana, el feto no puede ser considerado sujeto de derechos. Adicionalmente, afirmó la gradualidad de protección de la vida de que está por nacer, evitando tesis binarias que resuelven el asunto entre proteger/no proteger. Ambas consideraciones son

60 Almonacid Arellano y otros vs. Chile. Sentencia de excepciones preliminares, Fondo, Reparaciones y Costas. Sentencia del 26 de septiembre de 2006, Serie C No 154.

61 Gelman vs. Uruguay. Sentencia de fondo y Reparaciones. Sentencia de 24 de febrero de 2011 Serie C No 221. 
de especial importancia en Estados que prohíben absolutamente la interrupción del embarazo bajo la amenaza de una pena. Si se sigue la doctrina de control de convencionalidad de la Corte IDH, entonces la decisión en Artavia puede tener repercusiones nacionales en los Estados Parte.

\section{Citas Bibliográficas}

Acosta Alvarado, Paola Andrea \& Núnez Poblete, Manuel (2012): El Margen de Apreciación en el Sistema Interamericano de Derechos Humanos: Proyecciones Regionales y Nacionales (México, Universidad Nacional Autónoma de México). Benvenisti, Eyal (1999): "Margin of Appreciation, Consensus and Universal Standards", New York University Journal of International Law and Policy (New York, Vol. 31).

Carozza, Paolo G. (2003): "Subsidiarity as a Structural Principle of International Human Rights Law”, American Journal of International Law (Vol. 97).

Contreras, Pablo (2012): "National Discretion and International Deference in the Restriction of Human Rights: A Comparison Between the Jurisprudence of the European and the Inter-American Court of Human Rights", Northwestern Journal of International Human Rights (Vol. 11, No 1).

Duff, Patrick (1938): Personality in Roman Private Law (Cambridge University Press, Cambridge).

Feinberg, Joel (1986): “Abortion", en Regan, Tom (ed.): Matters of Life and Death: New Introductory Essays in Moral Philosophy (Random House, New York).

FigueroA, Rodolfo (2008): "Concepto de Derecho a la Vida”, Ius et Praxis (Vol. 14, No 1).

Kant, Immanuel (2003): Crítica de la Razón Pura (traducc. Pedro Rivas, Edit. Alfaguara, Madrid, Dialéctica Trascendental, Libro II, Capítulo I).

LEGG, Andrew (2012): The Margin of Appreciation in International Human Rights Law (Oxford Universty Press, Oxford).

PAúl, Alvaro (2013): "La Corte Interamericana in Vitro: Comentarios sobre su Proceso de Toma de Decisiones a Propósito del Caso Artavia", Revista de Derecho Público Iberoamericano (UDD) (Vol. 2).

Singer, Peter (1993): Practical Ethics (Cambridge University Press, Cambridge). Tamayo y Salmorán, Rolando (1996): “El Sujeto del Derecho”, en Ernesto GarZÓN VALDÉs \& Francisco LAPORTA (eds.): Enciclopedia Iberoamericana de Filosofía, Vol. XI: El Derecho y la Justicia (Instituto de Filosofía del CSIC, Madrid). 
Tooley, Michael (2009): “Abortion: Why a Liberal View is Correct”, en Abortion: Three Perspectives (Oxford University Press, New York).

Trevarthen, Colwyn \& Vasudevi, Reddy (2007): "Consciousness in Infants", en Velmans, Max \& Susan Schneider (eds.): Blackwell Companion to Consciousness (Blackwell Publishers, Oxford).

Undurraga, Verónica (2011): "La Decisión sobre Aborto de la Corte Europea de

Derechos Humanos 'A, B and C v. Ireland' y su Importancia para el Sistema Interamericano", Anuario de Derecho Público UDP (Año 2011).

Velmans, Max \& Susan Schneider (2007): Blackwell Companion to Consciousness (Blackwell Publishers, Oxford).

Warren, Mary Anne (1996): "On the Moral and Legal Status of Abortion", Thomas Mappes \& David DeGrazia (eds.): Biomedical Ethics (McGraw-Hill, New York).

Warren, Mary Anne (2000): "The Moral Difference Between Infanticide and Abortion: A Response To Robert Card", Bioethics (Vol. 14, No 4, Blackwell Publishers, Oxford).

Watson, Johanna (2013): "Reproductive Health Information and Abortion Services: Standards Developed by the European Court of Human Rights", International Journal of Gynecology and Obstetrics (Vol. 122).

\section{Sentencias de la Corte Interamericana de Derechos Humanos}

Almonacid Arellano y otros vs. Chile. Sentencia de excepciones preliminares, fondo, reparaciones y costas. Sentencia del 26 de septiembre de 2006, Serie C No 154. Gelman vs. Uruguay. Sentencia de fondo y reparaciones. Sentencia de 24 de febrero de 2011 Serie C No 221.

Artavia Murillo y otros ("Fecundación in Vitro") vs. Costa Rica, Sentencia de excepciones preliminares, fondo, reparaciones y costas, Ser. C No 257, Nov. 28, 2012 (“Artavia”).

\section{Sentencia del Tribunal Constitucional de Chile}

Sentencia Tribunal Constitucional, Rol No 740-2007.

\section{Sentencia de la Corte Suprema Federal de Estados Unidos}

Roe v. Wade 410 U.S. 113 [1973].

City of Akron v. Akron Center for Reproductive Health, Inc., 462 U.S. 416 (1983). 
Thornburgh v. American College of Obstetricians and Gynecologists, 106 S. Ct. 2169 (1986).

Sentencia del Tribunal Constitucional de España

Sentencia No 53/1985.

\section{Sentencia del Tribunal Constitucional Federal de Alemania}

Sentencia BverfGE 39,1 [1975].

Sentencia 88 BVerfGE 203 [1993].

Sentencia de la Corte Suprema de la Nación de México

Sentencia No $146 / 2007$ y su acumulada No $147 / 2007$.

Sentencia de la Corte Constitucional de Colombia

Sentencia C-355/2006.

Sentencias del Tribunal Europeo de Derechos Humanos

Sentencia del TEDH, Handyside v. United Kingdom, App. No 5493/72, Dic,. 7, 1976.

Sentencia del TEDH, Otto-Preminger-Institut v. Austria, App. No 13470/87, Sept. 20, 1994.

Sentencia del TEDH, Dudgeon v. Reino Unido, App. No 7525/76, Feb. 24, 1983

Sentencia del TEDH, Christine Goodwin v. Reino Unido, App. № 28957/95, Jul. 11, 2002.

Sentencia del TEDH, I v. Reino Unido, App. No 25680/94, Jul. 11, 2002.

Sentencia del TEDH, Vo v. Francia, App. No 53924/00, julio 8, 2004.

Sentencia del TEDH, Sahin v. Turquía, App. No 44774/98, Nov. 10, 2005.

Sentencia del TEDH, Evans v. Reino Unido, App. No 6339/05, abril 10, 2007.

Sentencia del TEDH, $A$, By C v. Irlanda, App. No 25579/05, diciembre 16, 2010.

Sentencia del TEDH, Lautsi v. Italia, App. No 30814/06, Mar. 18, 2011.

Sentencia del TEDH, S.H. y otros v. Austria, App. No 57813/00, noviembre 3, 2011.

Sentencia del TEDH, Costa y Pavan v. Italia, App. No 54270/10, agosto 28, 2012. 